\title{
How Investment Performance Affects the Formation and Use of Beliefs
}

\author{
Daniel Grosshans ${ }^{\mathrm{a}}$, Ferdinand Langnickel ${ }^{\mathrm{a}}$, and Stefan Zeisberger ${ }^{* \mathrm{~b}}$ \\ a Department of Banking and Finance, University of Zurich, Plattenstrasse 32, 8032 Zurich, Switzerland

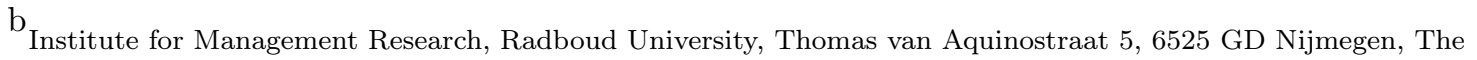 \\ Netherlands
}

May 22, 2017

\begin{abstract}
This study provides new insights on how investors form beliefs about future asset prices and how they use these beliefs for their trading decisions. Compared to the objective Bayesian benchmark, investors become overly optimistic when they face a paper loss. In addition, selling decisions are less sensitive to beliefs than purchase decisions. This difference is driven by selling behavior in the presence of paper losses. Our insights stem from a laboratory experiment in which participants are price-takers and trade a stock governed by a persistent two-state Markov chain. At each point in time, we elicit incentivized beliefs about the probability that the stock price will increase in the next period.
\end{abstract}

Keywords: behavioral finance, experimental finance, individual investors, trading behavior, belief formation

JEL classification: G11, G17

\footnotetext{
${ }^{*}$ We thank Tobias Gesche, Thorsten Hens, and seminar participants at the $8^{\text {th }}$ Thurgau Experimental Economics Meeting, and the University of Zurich for helpful comments and suggestions. This research was gratefully supported by the Swiss National Science Foundation (100018-149934). All remaining errors are ours.
} 


\section{Introduction}

A well-known stylized fact in behavioral finance is that individual investors actively trade single stocks (Barber and Odean, 2000). A key determinant of these trades is the investor's belief about the future development of the stock price. But, how are these beliefs formed? And, how are they incorporated into trading decisions of investors? To answer these questions, trading decisions and beliefs need to be observed simultaneously. However, empirical studies usually observe trading decisions and prices but not beliefs; and even experimental studies typically analyze the trading behavior or the belief formation of investors separately. In this paper we present results from a laboratory trading experiment that overcomes exactly this shortcoming. Our data allow us to study the impact of trading performance on the formation of individual investors' beliefs and on the belief sensitivity of their trading decisions.

We analyze whether investors' beliefs about the future development of a stock price are only determined by relevant information or whether other factors that are irrelevant to the development of the price alter investors' beliefs, as well. In particular, we hypothesize that investors have overly optimistic beliefs if they have experienced losses with their current investment. Chang et al. (2016) recently showed that trading decisions are affected by cognitive dissonances which is the disutility individuals experience when they recognize that their actions and beliefs are inconsistent with each other. They explain that investors tend to hold on to their losing stocks partly to avoid the pain of admitting an investment mistake. In this study, we provide evidence that this mechanism is facilitated by a belief channel which positively distorts beliefs in the presence of losses.

Moreover, we study the role of beliefs for buying and selling decisions. Barber and Odean (2013) postulate that buying and selling decisions are driven by different thought processes, and they suggest that buying decisions are more forward-looking than selling decisions. While we provide supporting evidence for their hypothesis by comparing the belief sensitivity of buying and selling decisions, we further show that this difference is driven by selling decisions in the loss domain where the sensitivity to beliefs is significantly reduced compared to the gain domain.

Our research questions require a trading environment where participants can intuitively form beliefs about future stock prices and are incentivized to both report their beliefs and also trade on them. We designed an experiment in which participants had to decide repeatedly whether to buy or sell, or not to trade an artificial stock; in addition, they had to provide forward-looking estimates of the probability of a price 
increase in the next period. The stock price dynamics were driven by a persistent two-state Markov process which created positive (negative) short-term momentum of stock prices in the good (bad) state. Thus, participants could use past prices form beliefs and make their trading decisions. The final earnings were based on trading performance and forecast accuracy such that all decisions and probability estimates were (potentially) payment relevant.

To address our first research question we utilize Bayes' rule to compute the objective probability of a price increase for each observation. While participants are unlikely to make perfect Bayesian probability estimates, it should be expected that their estimation errors are not systematically affected by a participant's current investment performance once we control for the objective probability. Nevertheless, we find that probability estimates in the loss domain are 2.3 percentage points larger than in the gain domain when controlling for the objective probability.

Our experiment provides a simple and intuitive rationale to trade, namely, to be invested in the stock whenever it is "sufficiently" likely to be in the good state. Importantly, the logic applies to buying as well as selling decisions. Thus, buying and selling should be equally forward-looking in our trading experiment. Nevertheless, we find that selling decisions are less sensitive to beliefs than buying decisions. In addition, we show that this difference is driven by selling decisions in the loss domain. Selling the stock at a gain is as sensitive to beliefs as buying decisions. However, we show that this sensitivity is reduced by about $50 \%$ once the investment yields a paper loss.

We provide novel insights to the finance literature on the belief formation of investors. There is a large body of literature on how people use past prices to form expectations about the future. Investors have been shown to overweight their personal experience and extrapolate past price trends (De Bondt, 1993; Fisher and Statman, 2000, 2002; Greenwood and Shleifer, 2014; Malmendier and Nagel, 2011). In line with that, Beshears et al. (2013) find that people struggle to recognize mean-reversion in price sequences; especially if it resolves slowly over time. We add to this literature by taking into account that investors may hold, buy, or sell a stock when they form beliefs about its future prices.

Investors' beliefs have been shown to be affected by previous investment choices and the investment environment using a related two-state experimental paradigm. Kuhnen (2015) shows that people form more pessimistic beliefs in environments where only losses are possible compared to environments where only gains are possible. Kuhnen and Knutson (2011) and Kuhnen et al. (2015) find that investors neglect new 
information when it is not in line with their previous trading decisions. In particular, participants who chose to invest in a stock instead of a bond underweighted negative information about the stock and vice versa. In this study, we address a related but distinct research question, namely, whether the formation and the use of beliefs is affected by the current performance of an investment position. Our results indicate that in addition to past prices the current performance of an investment position systematically affects the belief formation. Controlling for the objective probability we find that investors with losing positions report more positive beliefs than with winning positions.

Moreover, this study contributes to the knowledge about the trading behavior of individual investors. Many important insights have been found by empirical studies that analyze actual trades of individual investors (see, e.g. Barber and Odean, 2008; Barber et al., 2009; Chang et al., 2016; Goetzmann and Kumar, 2008; Grinblatt and Keloharju, 2001). In particular, investors have been shown to frequently engage in speculative trading (Barber and Odean, 2000). But the evidence on the link between beliefs and trading behavior is relatively sparse. Matching trades of retail investors in the UK with survey-based return expectations Merkle and Weber (2014) show that the portfolio risk of investors is positively associated with their market expectations. This finding is confirmed by Amromin and Sharpe (2014) who use data from the Michigan Surveys of Consumer Attitudes to study how risk and return expectations vary with beliefs about the general economic conditions. Buy-sell ratios, on the other hand, could not be explained by quantitative or qualitative measures of return expectations (Hoffmann et al., 2013; Merkle and Weber, 2014). Here, we propose a new experimental paradigm to study the belief sensitivity of buying and selling decisions at the stock level, separately. Motivated by the fact that investors tend to sell their winning stocks more readily than their losing stocks (Weber and Camerer, 1998; Odean, 1998; Shefrin and Statman, 1985) we compare the belief sensitivity of selling decisions in the gain and loss domain. Our results show a large reduction in the belief sensitivity of selling decisions if the investment position is at a loss.

\section{Experimental Design}

Our experiment is designed to simultaneously analyze beliefs and trading decisions of individual investors. Each participant was endowed with 170 experimental currency units (ECU) to trade an artificial stock over 40 periods. The endowment was equivalent to 17.0 CHF (approximately 17.0 USD at the time of the experiment). In 
each period, participants decided to buy or sell the stock, or to not trade. Additionally, they estimated the probability of a price increase to the next period on a scale from $30 \%$ to $70 \%^{1}$. The final earnings of a participant were composed of the sum of her final wealth at the end of the trading session plus an additional amount based on the precision of the probability estimate of one randomly drawn period. The exact payoff for the probability estimates depended on the absolute deviation from the true value. For simplicity, we chose the following discrete payment scheme: participants received 5, 3, or $1 \mathrm{CHF}$ if their estimation error was between 0 and $1 \%, 1 \%$ and $3 \%$, or $3 \%$ and $5 \%$, respectively. If the estimation error was larger than $5 \%$ there was no additional payment.

Stock price changes were determined by a persistent two-state Markov process that could attain a good or a bad state, as used by Frydman et al. (2014), Frydman and Rangel (2014), and Frydman et al. (2015). ${ }^{2}$ In the good state the stock price increased with $70 \%$ probability to the next period, while in the bad state the stock price decreased with $70 \%$ probability. The size of the price change was either 3 ECU, 6 ECU, or 9 ECU with equal probabilities, and independent of the state. Once the price change was determined there was a $20 \%$ probability for a state switch to the next period. The initial state of the stock randomly determined with $50 \%$ probability of starting in either state. As a consequence, the stock exhibited short term momentum and provided participants with an incentive to trade based on their beliefs. Participants knew the details of the stock price mechanism and saw the evolution of prices on a chart together with information on the current stock price, their cash holdings, and the gain or loss of their current position (see Figure 4 in Appendix A). To make sure that participants understood the task and were familiar with the trading environment they had to pass six comprehension questions and complete five trial periods of the trading game. At the end of the survey participants filled out a questionnaire that included self-reported measures of socio-demographics, risk preferences, financial and statistical knowledge, and satisfaction with their trading gains.

We generated a new price path for every participant to avoid path dependence effects of our results. As a consequence, participants observe different price sequences and their beliefs may rationally differ in any given period. To analyze the impact

\footnotetext{
${ }^{1}$ We chose to limit the probability estimates to values between $30 \%$ and $70 \%$ since these coincide with the estimates in case of full knowledge about the state of the stock. Two comprehension questions made sure that participants were aware that choosing a limit estimate meant that they were $100 \%$ sure that the stock is in the good or bad state.

${ }^{2}$ However, the price dynamics are slightly different to these studies since in our setting it is the current state which determines the distribution of possible price changes from the current to the next period.
} 
of trading performance on the belief formation we exploit the fact that, conditional on a certain objective probability, the beliefs of participants should rationally be the same.

In our setting the objective probability can be computed using Bayes' rule as follows. Let $s_{t}=\{$ good, bad $\}$ denote the state of the stock in period $t$. The price of the stock in period $t$ is given by $p_{t}$. Let $q_{t}^{s}=\mathbb{P}\left(s_{t}=1 \mid p_{s}, p_{s-1}, \ldots, p_{0}\right)$ denote the conditional probability that the stock is in the good state in period $t$ conditional on observing all prices up to period $s$. The prior probability that the stock starts in the good state is 0.5 , i.e. $q_{0}^{0}=0.5$. Beginning in period $t=1$ the observed price changes $\Delta p_{t}=p_{t}-p_{t-1}$ can be used to update the probability that the stock in the previous period was in the good state. Applying Bayes' rule we get

$$
\begin{aligned}
q_{t-1}^{t} & =\mathbb{P}\left(s_{t-1}=1 \mid p_{t}, p_{t-1}, \ldots\right) \\
& =\frac{q_{t-1}^{t-1} \mathbb{P}\left(\Delta p_{t} \mid s_{t-1}=1\right)}{q_{t-1}^{t-1} \mathbb{P}\left(\Delta p_{t} \mid s_{t-1}=1\right)+\left(1-q_{t-1}^{t-1}\right) \mathbb{P}\left(\Delta p_{t} \mid s_{t-1}=0\right)} .
\end{aligned}
$$

Note that the conditional probabilities of the stock price changes only depend on the sign of the price change (not the magnitude) and are given by

$$
\begin{aligned}
& \mathbb{P}\left(\Delta p_{t}>0 \mid s_{t-1}=1\right)=1-\mathbb{P}\left(\Delta p_{t}>0 \mid s_{t-1}=0\right)=0.7, \text { and } \\
& \mathbb{P}\left(\Delta p_{t}<0 \mid s_{t-1}=1\right)=1-\mathbb{P}\left(\Delta p_{t}<0 \mid s_{t-1}=0\right)=0.3 .
\end{aligned}
$$

Since the state of the stock switches to the next period with probability $0.8, q_{t}^{t}$ is given by

$$
q_{t}^{t}=0.8 q_{t-1}^{t}+0.2\left(1-q_{t-1}^{t}\right)
$$

The updated probability of an increase is finally obtained by using the state-dependent distribution of stock returns and the updated state probability

$$
\mathbb{P}\left(\Delta p_{t+1}>0 \mid p_{t}, p_{t-1}, \ldots\right)=0.7 q_{t}^{t}+0.3\left(1-q_{t}^{t}\right)
$$

It is important to note that the probability of a price increase is larger than $50 \%$ if and only if $q_{t}^{t}>0.5$. Due to the persistency of the state process the risk-neutral, rational trading strategy is therefore to buy and hold the asset whenever $q_{t}^{t}>0.5$, and sell the asset otherwise.

We recruited 63 advanced undergraduate and graduate students (39 male, 74.6\% graduate, median age: 24 years) from the University of Zurich to take part in a laboratory experiment. Students were required to have a study background in economics, 
finance or business administration. The experiment took place in the computer laboratory at the Department of Banking and Finance of University of Zurich. Participants received printed instructions ${ }^{3}$ before they completed the experiment on the computers. After the instructions, each participant proceeded at her own speed. Sessions lasted for about 50 minutes including instructions, trial periods, and payment procedure (26:23 min on average for the actual experiment including trial periods). Participants' final earnings ranged between 8.9 and 25.0 CHF.

\section{Results}

\subsection{Belief Formation}

We begin by addressing our first research question, i.e. if past investment performance with a particular asset affects belief formation, before we analyze the second one, namely how investors use their beliefs for their investment decisions in the following section.

We find that the performance of the current investment position affects the beliefs of our participants about the probability that the stock price will increase in systematic ways. In particular, when controlling for the objective probability we observe that participants report more optimistic beliefs when their position is at a loss than when their position is at a gain.

The effect of the investment performance on beliefs can be seen in Figure 1. It shows the average deviations of the probability estimates from the objective probabilities in response to a positive or negative price change for losing as well as winning positions. Rationally, the average beliefs should coincide with the objective benchmark. Looking at the average forecast errors after a positive price change one can see that beliefs are generally too optimistic in both the loss and the gain domain. It appears that this optimism is more pronounced in the loss domain as the distance to the objective probability is larger. After negative price changes there is a clear difference between the gain and loss domain. While beliefs in the presence of a gain are too pessimistic after a negative price change, probability estimates in the presence of a loss coincide with the rational benchmark. Thus, the belief formation appears to be different in the loss and gain domain resulting in more optimistic beliefs in the presence of losses.

We can formally test this observations in a linear regression model. In particular,

\footnotetext{
${ }^{3}$ The complete instructions of the experiment can be found here.
} 


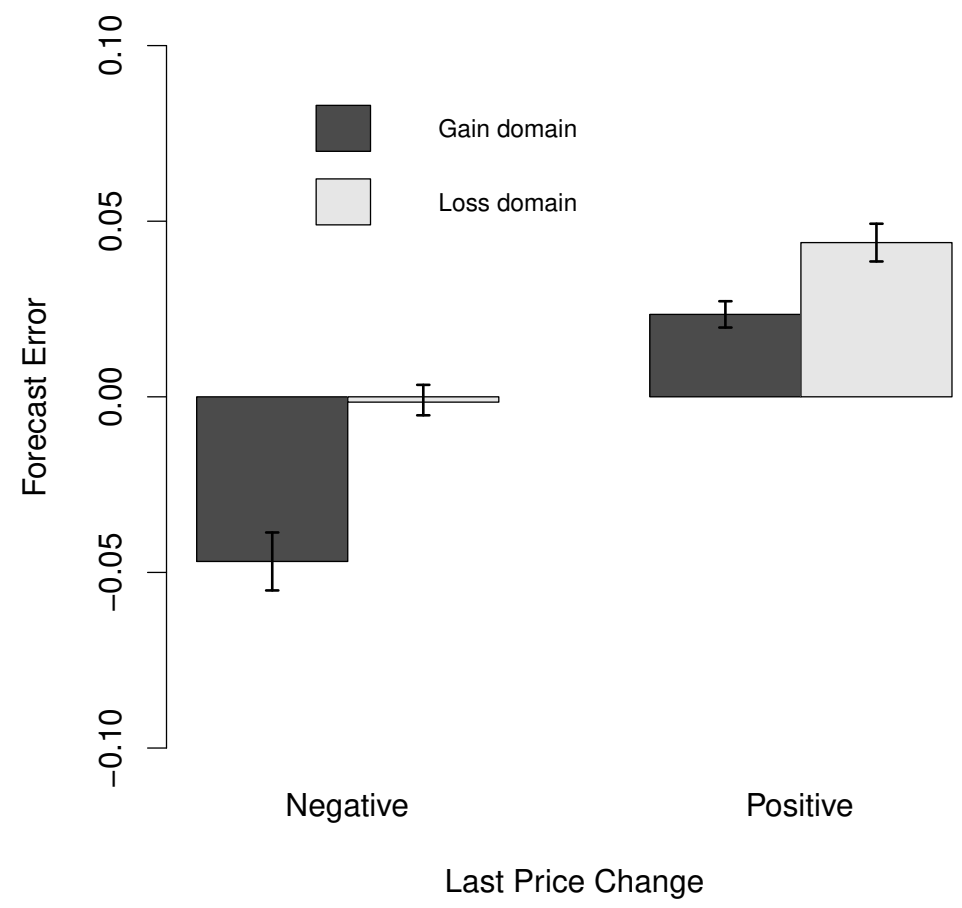

Figure 1: Average forecast errors after negative and positive price changes in the gain and loss domain.

we want to test if, when controlling for the objective probability, the beliefs of participants are systematically biased upwards by the fact that their current investment position is at a loss. We estimate the following fixed-effects panel regression

$$
\text { Belief }_{i, t}=\alpha_{i}+\beta_{1} \text { Objective probability }_{i, t}+\beta_{2} \mathbb{1}_{\text {Loss } i, t}+\beta_{3} \mathbb{1}_{\text {Not Invested } i, t}+u_{i, t}
$$

where the dependent variable Belief $_{i, t}$ is the probability estimate that the stock price will increase of participant $i$ in period $t$. The dummy variables $\mathbb{1}_{\text {Loss } i, t}$ and $\mathbb{1}_{\text {Not invested } i, t}$ indicate whether the participant $i$ is at a loss or not invested in period $t$, respectively. Our main interest is in the coefficient of the loss dummy which rationally should not be significant since we control for the objective probability. Table 1 reports the regression results. The coefficient of the objective probability is not significantly different from 1 which indicates that participants understood the price dynamics fairly well. However, the coefficient of the loss dummy shows that, controlling for the objective probability, the beliefs in the loss domain are on average 2.3 percentage points larger than in the gain domain $(p<0.01)$. The result remains 
robust if we control for the probability estimate of the previous period. When participants are not invested their beliefs are not significantly different to when their position is at a gain.

The trading performance in our experiment is endogenous. This is crucial as the belief channel we aim to identify requires that participants can actively buy and sell the stock. This endogeneity might be a potential concern for our finding as one could expect participants who are better in inferring probabilities to rarely face a loss. However, the stochastic properties of the stock price dynamics limit this problem to a large extent because all participants - regardless of their skill - will be frequently exposed to both gains and losses. This can be seen by looking at the number of loss observations of the best performing participants. To assess the performance of our participants we take into account that the price path is different for every participant and therefore differences in total gains from trade can be partly driven by random differences of the price path. Thus, we adjust the gains from trade of each participant by the trading gains that a risk-neutral, rational Bayesian investor would achieve for the same price path. We find that the top quintile of our participants on average faces a loss in 8.8 periods, or equivalently $34.8 \%$ of the time they are invested. Thus, even the best participants in our experiment are frequently exposed to losses.

Our result complements findings in Kuhnen and Knutson (2011) and Kuhnen et al. (2015) who show that people insufficiently update their beliefs to information that is in contradiction with their previous investment choices. We demonstrate that the belief formation not only depends on previous investment choices but also on the current investment performance. This result is in line with the existence of a belief channel that helps to alleviate cognitive dissonances caused by the friction between the initial investment decision and current loss of a position. If the investment is at a loss, participants' beliefs are more optimistic than they would be in the same situation if their position was at a gain. Our experimental design excludes rational reasons for this findings.

\subsection{Use of Beliefs: Trading Behavior}

We now turn to our second question, namely how beliefs affect the trading decisions of investors. We generally find that trading decisions of our participants are belief-driven. This can be seen in Figure 2 which shows average probability estimates around trading decisions together with the objective probabilities. The left panel shows beliefs around buying decisions. On average, purchases coincide with very op- 
Table 1: Belief regression

This table shows the estimation results of fixed effects regression models to explain the belief formation of participants. The dependent variable Belief $_{i, t}$ is the probability estimate of a price increase. The independent variables are defined as follows: Objective probability ${ }_{i, t}$ is the objective probability based on Bayes' rule; $\mathbb{1}_{\text {Not invested } i, t}$ is an indicator equal to one if the participant is not invested in the stock; $\mathbb{1}_{\text {Loss domain } i, t}$ is an indicator equal to one if the current gain of the investment is negative; Belief ${ }_{i, t-1}$ is the probability estimate of the previous round. Heteroscedasticity-consistent (HC3) standard errors clustered at the individual level are reported in parentheses. ${ }^{* * *}$, **, and * indicate significance levels at the $1 \%, 5 \%$, and $10 \%$ level, respectively.

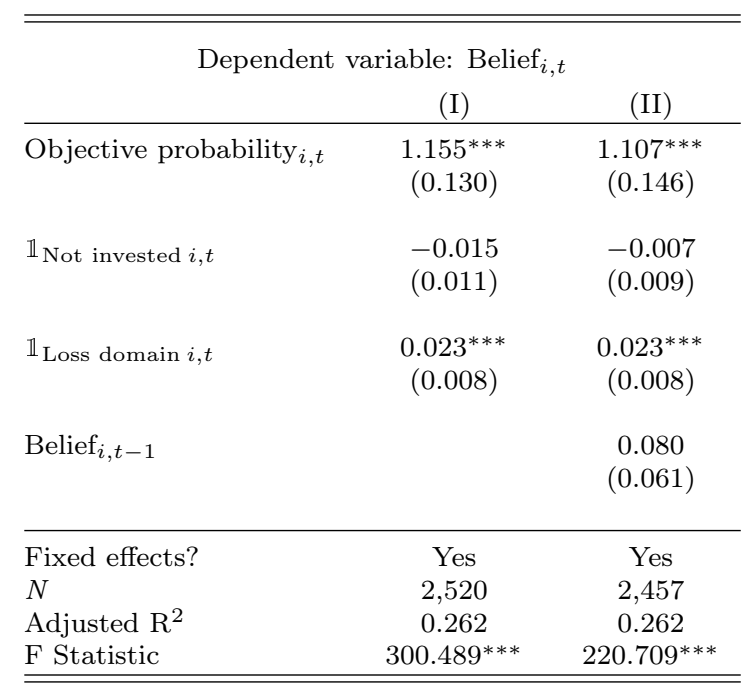

timistic beliefs and occur at times when the objective probability is greater than $50 \%$. Interestingly, the beliefs in the period previous to the purchase are fairly pessimistic and the true probability is below $50 \%$. This suggests that participants tend to buy after reversals. The right panel of Figure 2 shows beliefs around selling decisions. Here, we observe the reverse-pattern of the buying decisions. Sales coincide with very pessimistic beliefs and the beliefs in the period before a sale are very optimistic.

To compare the sensitivity of buying and selling decisions with respect to the beliefs of participants we first analyze the decision to be invested, i.e. we compute an indicator variable that equals one if the participants decides to buy or hold the stock and zero otherwise. We then estimate the following linear regression model with the decision to be invested as dependent variable

$$
\mathbb{1}_{\text {Invest } i, t}=\alpha_{i}+\beta_{1} \text { Belief }_{i, t}+\beta_{2} \mathbb{1}_{\text {Long } i, t}+\beta_{3} \text { Belief }_{i, t} \times \mathbb{1}_{\text {Long } i, t}+\gamma X_{i, t}+u_{i, t} .
$$

The independent variables are Belief $_{i, t}$ which is the probability estimate that the stock price will increase, a dummy variable $\mathbb{1}_{\text {Long } i, t}$ indicating whether the participant $i$ is long in the stock in period $t$, and the interaction between the two variables. In addition, we can include a vector of control variables $X_{i, t}$. We expect that the decision 
Buying

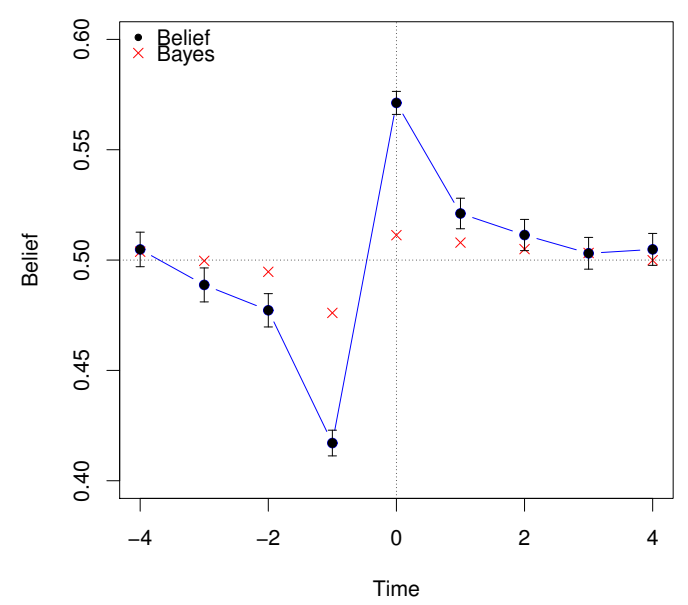

Selling

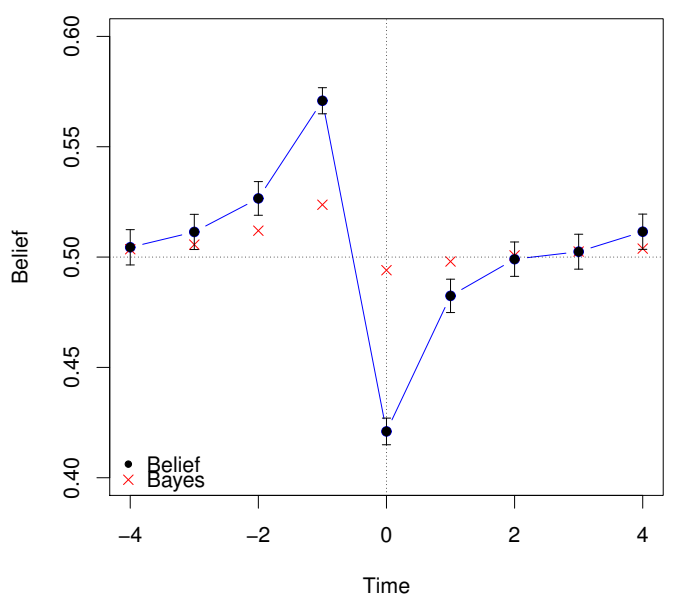

Figure 2: Average beliefs around buying and selling decisions. The x-axis shows the timeline from four rounds before and after the trade. At time zero the trade takes place. The red crosses indicate the average objective probability.

to be invested is positively related to beliefs. Ex-ante there should be no difference in the sensitivity of buying and selling decisions with respect to beliefs. If, however, selling is less sensitive to beliefs (less forward-looking) than buying, the coefficient of the interaction variable should be negative.

The regression results are reported in Table 2 (the results remain the same if we estimate logit or probit models see Table 4 in Appendix A). First of all, we find that the decision to be invested is significantly positively related to beliefs independent of whether the participant is invested or not $(p<0.01) .{ }^{4}$ Indeed, we find that the decision to be invested is significantly less sensitive to beliefs if the participant is invested $(p<0.05)$. The interaction reduces the sensitivity by about 25 percent. The result remains the same if we additionally control for the current wealth and price change. Thus, selling decisions are less sensitive to beliefs than buying decisions.

It is well-known that selling behavior is different in the gain and loss domain. Therefore, we now address the question whether the reduced sensitivity of selling decisions with respect to beliefs applies to the gain domain as well as the loss domain. A visual comparison of the belief distribution in the gain and loss domain suggests that beliefs play a different role for selling decisions in the loss domain. Figure 3 shows the histograms of beliefs in the gain and loss domain. Each bar is split into observations that coincide with a decision to sell or hold. The distribution in the

\footnotetext{
${ }^{4}$ Note that this result rules out potential hedging concerns. If participants hedged their investment positions with their probability estimates the relation should be negative.
} 
Table 2: Investment decision regressions.

This table shows the estimation results of fixed effects linear regression models to explain the investment decisions of participants. The dependent variable $\mathbb{1}_{\text {Invest } i, t}$ is an indicator equal to one if the subject decides to be invested in the stock until the next round. The independent variables are defined as follows: Belief $_{i, t}$ is the probability estimate of a stock price increase; $\mathbb{1}_{\text {Long } i, t}$ is an indicator equal to one if the participant is invested in the stock; Wealth ${ }_{i, t}$ is the current wealth of the participant in ECU; $\Delta$ Price $_{i, t}$ is the last price change in ECU. Heteroscedasticity-consistent (HC3) standard errors clustered at the individual level are reported in parentheses. ${ }^{* * *},{ }^{* *}$, and ${ }^{*}$ indicate significance levels at the $1 \%, 5 \%$, and $10 \%$ level, respectively.

\begin{tabular}{lcc}
\hline \hline Dependent variable: & \multicolumn{2}{c}{$\mathbb{1}_{\text {Invest } i, t}$} \\
& $(\mathrm{I})$ & $(\mathrm{II})$ \\
\hline Belief $_{i, t}$ & $(0.282)$ & $(0.281)$ \\
& & \\
& & \\
Belief $_{i, t} \times \mathbb{1}_{\text {Long, } i, t}$ & $\left(0.602^{* *}\right.$ & $-0.567^{* * *}$ \\
& $(0.281)$ & $(0.280)$ \\
& $0.629^{* * *}$ & $0.609^{* * *}$ \\
$\mathbb{1}_{\text {Long, } i, t}$ & $(0.137)$ & $(0.134)$ \\
& & \\
Wealth $_{i, t}$ & & $-0.002^{* * *}$ \\
& & $(0.001)$ \\
$\Delta$ Price $_{i, t}$ & & 0.002 \\
& & $(0.002)$ \\
\hline Fixed effects? & & \\
$N$ & & Yes \\
Adjusted R & & 2,520 \\
F Statistic & Yes & 0.363 \\
\hline \hline
\end{tabular}



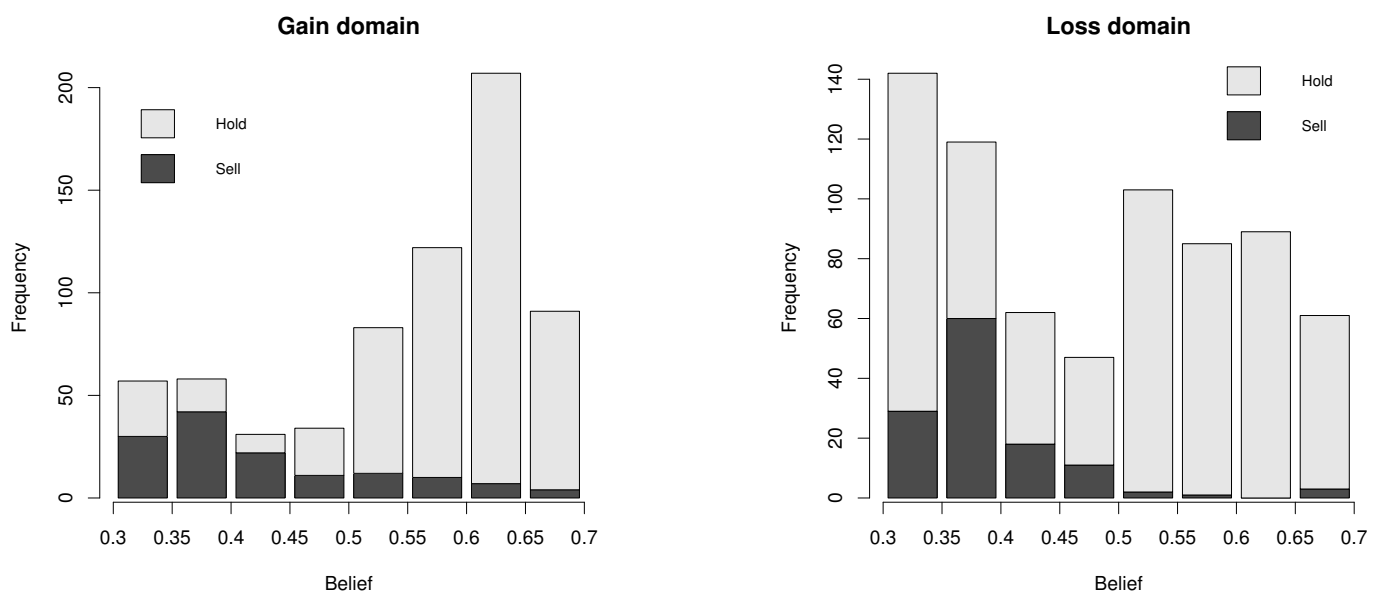

Figure 3: Histograms of probability estimates when participants are invested in the stock split by the current gain of the investment. The left panel shows the histogram of the gain domain, the right panel shows the histogram of the loss domain.

gain domain (left panel) shows a clear pattern: the majority of sales coincide with relatively pessimistic beliefs while decisions to hold the stock are mostly observed at optimistic beliefs. In the loss domain (right panel), however, the relationship is less clear. Here, participants tend to sell the stock at pessimistic beliefs, but they are also likely to hold the stock at very pessimistic beliefs. Thus, it appears that selling decisions in the loss domain are less sensitive to beliefs than selling decisions in the gain domain.

To formally test the reduced belief-sensitivity in the loss domain we split the data into observations where participants are invested and observations where they are not invested. We can then estimate the following regression model to explain selling decisions using only the observations where participants are invested

$$
\mathbb{1}_{\text {Sell i,t }}=\alpha_{i}+\beta_{1} \text { Belief }_{i, t}+\beta_{2} \mathbb{1}_{\text {Loss } i, t}+\beta_{3} \text { Belief }_{i, t} \times \mathbb{1}_{\text {Loss } i, t}+\gamma X_{i, t}+u_{i, t} .
$$

To compare the sensitivity of selling decisions with buying decisions we additionally estimate the following regression model to explain buying decisions using the remaining data

$$
\mathbb{1}_{\text {Buy } i, t}=\alpha_{i}+\beta_{1} \text { Belief }_{i, t}+\gamma X_{i, t}+u_{i, t} .
$$

Table 3 shows the regression results of both linear models. The results stay the same if we use logit or probit models (see Table 5 and Table 6 in Appendix A). In total we estimate six regression models. Models (I) and (II) explain buying decisions based on the regression model (8) . Models (III) to (VI) explain selling decisions based 
on regression model (7). In Models (III) and (IV) we regress selling decisions on beliefs and control variables and add an interaction term of beliefs and a loss domain dummy in models (V) and (IV). Comparing the absolute size of the coefficients of the probability estimate between model (I)-(II) and (III)-(IV) confirms our previous results that the sensitivity of selling decisions is reduced by about $25 \%$ compared to buying decisions. But introducing the interaction term in models (V) and (VI) shows that this difference is driven by selling decisions in the loss domain. The sensitivity of selling decisions to beliefs is significantly reduced if the investment is at a loss $(p<0.01)$. The sensitivity is reduced by about $50 \%$ and the finding is robust if we control for the current ECU holdings and the most recent price change. Moreover, we find that the sensitivity of selling decisions in the gain domain is not different from the sensitivity of buying decisions. In other words, the decision to sell a position at a gain is as belief-driven as a purchase decision while selling a position at a loss depends significantly less on beliefs.

Table 3: Trading decision regressions.

This table reports estimation results of fixed-effects linear regression models to explain buying and selling decisions. Models (I) and (II) explain buying decisions and models (III) to (VI) explain selling decisions. The dependent variable in models (I) and (II) is an indicator equal to one if the investment decision is to buy the stock. In models (III) to (VI) the dependent variable is an indicator equal to one if the investment decision is to sell the stock. The independent variables are defined as follows: Belief $_{i, t}$ is the probability estimate for a price increase; Wealth ${ }_{i, t}$ is the current wealth in ECU; $\Delta$ Price $_{i, t}$ is the last price change in ECU, and $\mathbb{1}_{\text {Loss domain } i, t}$ is a dummy variable equal to one if the current gain of the investment is negative. Heteroscedasticity-consistent (HC3) standard errors clustered by subject are reported in parenthesis. ${ }^{* * *},{ }^{* *}$, and ${ }^{*}$ indicate significance levels at the $1 \%, 5 \%$, and $10 \%$ level, respectively.

\begin{tabular}{|c|c|c|c|c|c|c|}
\hline \multirow[t]{2}{*}{ Dependent variable } & \multicolumn{2}{|c|}{ Buy indicator $_{i, t}$} & \multicolumn{4}{|c|}{ Sell indicator ${ }_{i, t}$} \\
\hline & $(\mathrm{I})$ & (II) & (III) & $(\mathrm{IV})$ & $(\mathrm{V})$ & $(\mathrm{VI})$ \\
\hline Belief $_{i, t}$ & $\begin{array}{c}1.993^{* * *} \\
(0.298)\end{array}$ & $\begin{array}{c}1.877^{* * *} \\
(0.317)\end{array}$ & $\begin{array}{c}-1.514^{* * *} \\
(0.225)\end{array}$ & $\begin{array}{c}-1.579^{* * *} \\
(0.230)\end{array}$ & $\begin{array}{c}-2.167^{* * *} \\
(0.270)\end{array}$ & $\begin{array}{c}-2.179^{* * *} \\
(0.284)\end{array}$ \\
\hline Wealth $_{i, t}$ & & $\begin{array}{l}-0.001 \\
(0.001)\end{array}$ & & $\begin{array}{c}0.001 \\
(0.001)\end{array}$ & & $\begin{array}{l}0.0005 \\
(0.001)\end{array}$ \\
\hline$\Delta$ Price $_{i, t}$ & & $\begin{array}{c}0.004 \\
(0.003)\end{array}$ & & $\begin{array}{c}0.002 \\
(0.002)\end{array}$ & & $\begin{array}{l}0.0004 \\
(0.002)\end{array}$ \\
\hline $\mathbb{1}_{\text {Loss domain, } i, t}$ & & & & & $\begin{array}{c}-0.620^{* * *} \\
(0.132)\end{array}$ & $\begin{array}{c}-0.614^{* * *} \\
(0.133)\end{array}$ \\
\hline Belief $_{i, t} \times \mathbb{1}_{\text {Loss domain }, i, t}$ & & & & & $\begin{array}{c}1.079^{* * *} \\
(0.242)\end{array}$ & $\begin{array}{c}1.082^{* * *} \\
(0.242)\end{array}$ \\
\hline Subject fixed effects? & Yes & Yes & Yes & Yes & Yes & Yes \\
\hline$N$ & 1,070 & 1,070 & 1,450 & 1,450 & 1,450 & 1,450 \\
\hline Adjusted $\mathrm{R}^{2}$ & 0.270 & 0.288 & 0.129 & 0.146 & 0.169 & 0.178 \\
\hline
\end{tabular}




\section{Conclusion}

In this paper we present evidence that the beliefs of investors about the future potential of an investment are influenced by their past investment performance. In particular, we demonstrate that when investors face a paper loss, they have significantly more optimistic beliefs than when their position is at a gain. Investors seem to experience cognitive dissonances in the loss domain (Chang et al., 2016) that prevent them from adjusting their beliefs to new information that casts doubt on their initial purchase decision. In a second step, we analyze how beliefs influence trading decisions. We find evidence that selling decisions are less forward-looking than buying decisions - a hypothesis that was claimed by Barber and Odean (2013). However, this finding does not apply to all selling decisions. Instead, we find that only selling decisions in the presence of paper losses are less sensitive to beliefs.

Combining our first and second finding, we identify a new channel through which losses affect the trading behavior of individual investors. While in the face of paper gains investors adequately take into account new information to determine their trading decisions, they react less to new information in the face of paper losses and even maintain overly optimistic beliefs. Those investors that are not yet invested in an asset or face paper gains are able to follow a rational investment strategy. In our experimental setting this means that they update their beliefs reasonably and use their beliefs to determine their trading decisions. However, in the face of losses investors seem to lose their ability to follow a rational strategy. They maintain overly optimistic beliefs and care less about incorporating their beliefs into their trading decisions.

Our results provide promising directions for future research. Investors' ability to form and use beliefs is distorted by losses. An important question is how this effect evolves over time. One can imagine that cognitive dissonances, for example, play a different role when the investor holds a losing stock since only a day compared to a week, or even a year. In addition, researchers may further explore the heterogeneity of investors. It would be interesting to identify certain types of investors to determine ex-ante which investors are more likely to be affected by losses. 


\section{References}

Ai, C., Norton, E.C., 2003. Interaction terms in logit and probit models. Economics Letters 80, 123-129.

Amromin, G., Sharpe, S.A., 2014. From the Horse's Mouth: How Do Investor Expectations of Risk and Return Vary with Economic Conditions? Management Science $60,845-866$.

Barber, B.M., Odean, T., 2000. Trading Is Hazardous to Your Wealth: The Common Stock Investment Performance of Individual Investors. Journal of Finance LV, 773-806.

Barber, B.M., Odean, T., 2008. All that Glitters: The effect of Attention and news on the Buying Behavior of Individual and Institutional Investors. Review of Financial Studies 21, 785-818.

Barber, B.M., Odean, T., 2013. The Behavior of Individual Investors, in: Constantinides, G.M., Harris, M., Stulz, R.M. (Eds.), Handbook of the Economics of Finance. Elsevier. volume 2, Part B. chapter 22, pp. 1533-1570.

Barber, B.M., Odean, T., Zhu, N., 2009. Do retail trades move markets? Review of Financial Studies 22, 151-186.

Beshears, J., Choi, J.J., Fuster, A., Laibson, D., Madrian, B.C., 2013. What goes up must come down? Experimental evidence on intuitive forecasting. American Economic Review 103, 570-574.

Chang, T., Solomon, D.H., Westerfield, M.M., 2016. Looking for Someone to Blame: Delegation, Cognitive Dissonance, and the Disposition Effect. Journal of Finance 71, 267-302.

De Bondt, W.F., 1993. Betting on trends: Intuitive forecasts of financial risk and return. International Journal of Forecasting 9, 355-371.

Fisher, K.L., Statman, M., 2000. Investor sentiment and stock returns. Financial Analysts Journal 56, 16-23.

Fisher, K.L., Statman, M., 2002. Blowing Bubbles. Journal of Psychology and Financial Markets 3, 53-66. 
Frydman, C., Barberis, N., Camerer, C., Bossaerts, P., Rangel, A., 2014. Using Neural Data to Test a Theory of Investor Behavior: An Application to Realization Utility. Journal of Finance 69, 907-946.

Frydman, C., Rangel, A., 2014. Debiasing the disposition effect by reducing the saliency of information about a stock's purchase price. Journal of Economic Behavior and Organization 107, 541-552.

Frydman, C.D., Hartzmark, S.M., Solomon, D.H., 2015. Rolling Mental Accounts. Working Paper .

Goetzmann, W.N., Kumar, A., 2008. Equity Portfolio Diversification. Review of Finance 12, 433-463.

Greenwood, R., Shleifer, A., 2014. Expectations of returns and expected returns. Review of Financial Studies 27, 714-746.

Grinblatt, M., Keloharju, M., 2001. What Makes Investors Trade? Journal of Finance $56,589-616$.

Hahn, J., Newey, W., 2004. Jackknife and analytical bias reduction for nonlinear panel models. Econometrica 72, 1295-1319.

Hoffmann, A.O.I., Post, T., Pennings, J.M.E., 2013. Individual investor perceptions and behavior during the financial crisis. Journal of Banking and Finance 37, 60-74.

Kuhnen, C.M., 2015. Asymmetric Learning from Financial Information. Journal of Finance 70, 2029-2062.

Kuhnen, C.M., Knutson, B., 2011. The Influence of Affect on Beliefs, Preferences, and Financial Decisions. Journal of Financial and Quantative Analysis 46, 605-626.

Kuhnen, C.M., Rudorf, S., Weber, B., 2015. Stock Ownership and Learning from Financial Information. Working Paper , 1-17.

Malmendier, U., Nagel, S., 2011. Depression Babies: Do Macroeconomic Experiences Affect Risk Taking? The Quarterly Journal of Economics 126, 373-416.

Merkle, C., Weber, M., 2014. Do investors put their money where their mouth is? Stock market expectations and investing behavior. Journal of Banking and Finance $46,372-386$. 
Norton, E.C., Wang, H., Ai, C., 2004. Computing interaction effects and standard errors in logit and probit models. Stata Journal 4, 154-167.

Odean, T., 1998. Are Investors Reluctant to Realize their Losses? The Journal of Finance 53, 1775-1798.

Shefrin, H., Statman, M., 1985. The Disposition to Sell Winners Too Early and Ride Losers Too Long: Theory and Evidence. The Journal of Finance 40, 777-790.

Weber, M., Camerer, C.F., 1998. The disposition effect in securities trading: an experimental analysis. Journal of Economic Behavior \& Organization 33, 167-184. 


\section{Appendix A Figures and Tables}

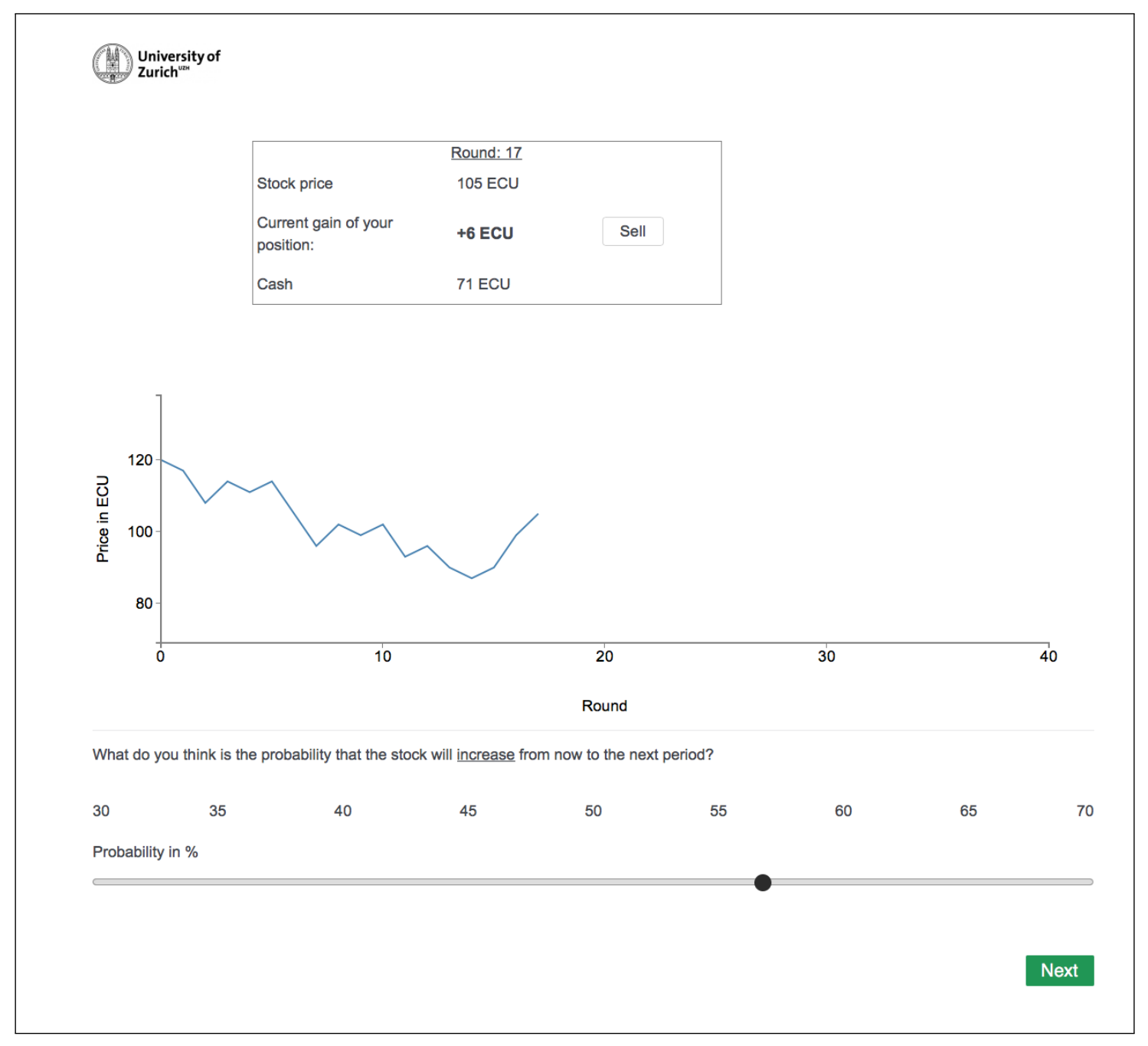

Figure 4: Screenshot of the trading game. 
Table 4: Non-linear investment decision regressions.

This table reports marginal effects of fixed-effects logit and probit models at the average regressor values. The regression coefficients are adjusted using the analytical bias correction for the incidental parameter problem (Hahn and Newey, 2004). Models (I) and (II) are logit models and models (III) to (VI) are probit models. In models (II) and (IV) the value of $\mathbb{1}_{\text {Long } i, t}$ is set to zero such that the marginal effect of the Belief variable captures the belief sensitivity of buying decisions. The dependent variable $\mathbb{1}_{\text {Invest } i, t}$ is an indicator equal to one if the subject decides to be invested in the stock until the next round. The independent variables are defined as follows: Belief $i_{i, t}$ is the probability estimate of a stock price increase; $\mathbb{1}_{\text {Long } i, t}$ is an indicator equal to one if the participant is invested in the stock; Wealth ${ }_{i, t}$ is the current wealth of the participant in ECU; $\Delta$ Price $_{i, t}$ is the last price change in ECU. Robust standard errors clustered by subject are reported in parenthesis. ${ }^{* * *},{ }^{* *}$, and ${ }^{*}$ indicate significance levels at the $1 \%, 5 \%$, and $10 \%$ level, respectively. Marginal effects of interaction terms are computed according to Norton et al. (2004).

\begin{tabular}{|c|c|c|c|c|}
\hline \multirow[t]{3}{*}{ Dependent variable: } & \multicolumn{4}{|c|}{$\mathbb{1}_{\text {Invest } i, t}$} \\
\hline & \multicolumn{2}{|c|}{ Logit } & \multicolumn{2}{|c|}{ Probit } \\
\hline & (I) & (II) & (III) & (IV) \\
\hline Belief $_{i, t}$ & $\begin{array}{c}3.410^{* * *} \\
(0.515)\end{array}$ & $\begin{array}{c}3.359^{* * *} \\
(0.508)\end{array}$ & $\begin{array}{c}3.067 \\
(0.433)\end{array}$ & $\begin{array}{l}3.006 \\
(0.431)\end{array}$ \\
\hline Belief $_{i, t} \times \mathbb{1}_{\text {Long }, i, t}$ & $\begin{array}{c}-1.649^{* * *} \\
(0.319)\end{array}$ & $\begin{array}{c}-1.575^{* * *} \\
(0.304)\end{array}$ & $\begin{array}{c}-1.305^{* * *} \\
(0.250)\end{array}$ & $\begin{array}{c}-1.236^{* * *} \\
(0.238)\end{array}$ \\
\hline $\mathbb{1}_{\text {Long, } i, t}$ & $\begin{array}{c}0.807^{* * *} \\
(0.176)\end{array}$ & $\begin{array}{c}0.737^{* * *} \\
(0.180)\end{array}$ & $\begin{array}{c}0.752^{* * *} \\
(0.140)\end{array}$ & $\begin{array}{c}0.705^{* * *} \\
(0.144)\end{array}$ \\
\hline Wealth $_{i, t}$ & & $\begin{array}{c}-0.004^{* * *} \\
(0.002)\end{array}$ & & $\begin{array}{c}-0.004^{* * *} \\
(0.001)\end{array}$ \\
\hline$\Delta$ Price $_{i, t}$ & & $\begin{array}{c}0.002 \\
(0.004)\end{array}$ & & $\begin{array}{c}0.002 \\
(0.003)\end{array}$ \\
\hline$N$ & 2,440 & 2,440 & 2,440 & 2,440 \\
\hline Log Likelihood & -928.838 & -918.455 & -936.651 & -927.437 \\
\hline
\end{tabular}


Table 5: Fixed-effects logit regression model.

This table reports marginal effects at the average regressor values. The regression coefficients are adjusted using the analytical bias correction for the incidental parameter problem (Hahn and Newey, 2004). In models (V) and (VI) the input value of $\mathbb{1}_{\text {Loss domain } i, t}$ is set to zero such that the marginal effect of the Belief variable captures the effect in the face of a gain. Models (I) and (II) explain buying decisions and models (III) to (VI) explain selling decisions. The dependent variable in models (I) and (II) is an indicator equal to one if the investment decision is to buy the stock. In models (III) to (VI) the dependent variable is an indicator equal to one if the investment decision is to sell the stock. The independent variables are defined as follows: Belief $f_{i, t}$ is the probability estimate for a price increase; Wealth ${ }_{i, t}$ is the current wealth in ECU; $\Delta$ Price $_{i, t}$ is the last price change in $\mathrm{ECU}$, and $\mathbb{1}_{\text {Loss domain } i, t}$ is a dummy variable equal to one if the current gain of the investment is negative.Robust standard errors clustered by subject are reported in parenthesis. ${ }^{* * *},{ }^{* *}$, and ${ }^{*}$ indicate significance levels at the $1 \%, 5 \%$, and $10 \%$ level, respectively. Marginal effects of interaction terms are computed according to Ai and Norton (2003).

\begin{tabular}{|c|c|c|c|c|c|c|}
\hline \multirow[t]{2}{*}{ Dependent variable } & \multicolumn{2}{|c|}{ Buy indicator $_{i, t}$} & \multicolumn{4}{|c|}{ Sell indicator ${ }_{i, t}$} \\
\hline & (I) & (II) & (III) & (IV) & $(\mathrm{V})$ & $(\mathrm{VI})$ \\
\hline Belief $_{i, t}$ & $\begin{array}{c}2.433^{* * * *} \\
(0.208)\end{array}$ & $\begin{array}{c}2.480^{* * *} \\
(0.238)\end{array}$ & $\begin{array}{c}-1.156^{* * *} \\
(0.001)\end{array}$ & $\begin{array}{c}-1.204^{* * *} \\
(0.054)\end{array}$ & $\begin{array}{c}-1.960^{* * *} \\
(0.248)\end{array}$ & $\begin{array}{c}-1.917^{* * *} \\
(0.240)\end{array}$ \\
\hline Wealth $_{i, t}$ & & $\begin{array}{l}-0.001 \\
(0.004)\end{array}$ & & $\begin{array}{l}0.001^{*} \\
(0.001)\end{array}$ & & $\begin{array}{c}0.001 \\
(0.001)\end{array}$ \\
\hline$\Delta$ Price $_{i, t}$ & & $\begin{array}{l}-0.001 \\
(0.004)\end{array}$ & & $\begin{array}{c}0.002 \\
(0.002)\end{array}$ & & $\begin{array}{l}-0.001 \\
(0.004)\end{array}$ \\
\hline $\mathbb{1}_{\text {Loss domain }, i, t}$ & & & & & $\begin{array}{c}-0.255^{*} \\
(0.139)\end{array}$ & $\begin{array}{c}-0.244^{*} \\
(0.143)\end{array}$ \\
\hline Belief $_{i t} \times \mathbb{1}_{\text {Loss domain, } i, t}$ & & & & & $\begin{array}{c}1.182^{* * *} \\
(0.355)\end{array}$ & $\begin{array}{c}1.158^{* * *} \\
(0.323)\end{array}$ \\
\hline $\begin{array}{l}N \\
\text { Log Likelihood }\end{array}$ & $\begin{array}{c}1,007 \\
-349.347\end{array}$ & $\begin{array}{c}1,007 \\
-348.602\end{array}$ & $\begin{array}{c}1,391 \\
-400.64\end{array}$ & $\begin{array}{c}1,391 \\
-396.056\end{array}$ & $\begin{array}{c}1,391 \\
-385.308\end{array}$ & $\begin{array}{c}1,391 \\
-384.904\end{array}$ \\
\hline
\end{tabular}


Table 6: Fixed-effects probit regression model.

This table reports marginal effects at the average regressor values. The regression coefficients are adjusted using the analytical bias correction for the incidental parameter problem (Hahn and Newey, 2004). In models (V) and (VI) the value of $\mathbb{1}_{\text {Loss domain } i, t}$ is set to zero such that the marginal effect of the Belief variable captures the effect in the face of a gain. Models (I) and (II) explain buying decisions and models (III) to (VI) explain selling decisions. The dependent variable in models (I) and (II) is an indicator equal to one if the investment decision is to buy the stock. In models (III) to (VI) the dependent variable is an indicator equal to one if the investment decision is to sell the stock. The independent variables are defined as follows: Belief $_{i, t}$ is the probability estimate for a price increase; Wealth $i, t$ is the current wealth in ECU; $\Delta$ Price $_{i, t}$ is the last price change in ECU, and $\mathbb{1}_{\text {Loss domain } i, t}$ is a dummy variable equal to one if the current gain of the investment is negative. Robust standard errors clustered by subject are reported in parenthesis. ${ }^{* * *},{ }^{* *}$, and ${ }^{*}$ indicate significance levels at the $1 \%, 5 \%$, and $10 \%$ level, respectively. Marginal effects of interaction terms are computed according to Norton et al. (2004).

\begin{tabular}{|c|c|c|c|c|c|c|}
\hline \multirow[t]{2}{*}{ Dependent variable } & \multicolumn{2}{|c|}{ Buy indicator $_{i, t}$} & \multicolumn{4}{|c|}{ Sell indicator ${ }_{i, t}$} \\
\hline & (I) & (II) & (III) & (IV) & $(\mathrm{V})$ & (VI) \\
\hline Belief $_{i, t}$ & $\begin{array}{c}2.539^{* * *} \\
(0.280)\end{array}$ & $\begin{array}{c}2.575^{* * *} \\
(0.313)\end{array}$ & $\begin{array}{c}-1.322^{* * *} \\
(0.101)\end{array}$ & $\begin{array}{c}-1.388^{* * *} \\
(0.125)\end{array}$ & $\begin{array}{l}-2.113^{* * *} \\
(0.303)\end{array}$ & $\begin{array}{c}-2.080^{* * *} \\
(0.305)\end{array}$ \\
\hline Wealth $_{i, t}$ & & $\begin{array}{l}-0.002 \\
(0.002)\end{array}$ & & $\begin{array}{c}0.001 \\
(0.001)\end{array}$ & & $\begin{array}{c}0.000 \\
(0.001)\end{array}$ \\
\hline$\Delta$ Price $_{i, t}$ & & $\begin{array}{l}-0.001 \\
(0.005)\end{array}$ & & $\begin{array}{c}0.002 \\
(0.003)\end{array}$ & & $\begin{array}{l}-0.001 \\
(0.004)\end{array}$ \\
\hline $\mathbb{1}_{\text {Loss domain }, i, t}$ & & & & & $\begin{array}{c}-0.332^{* *} \\
(0.144)\end{array}$ & $\begin{array}{c}-0.326^{* *} \\
(0.151)\end{array}$ \\
\hline Belief $_{i, t} \times \mathbb{1}_{\text {Loss domain }, i, t}$ & & & & & $\begin{array}{c}1.180^{* * *} \\
(0.366)\end{array}$ & $\begin{array}{c}1.169^{* * *} \\
(0.345)\end{array}$ \\
\hline $\begin{array}{l}N \\
\text { Log Likelihood }\end{array}$ & $\begin{array}{c}1,007 \\
-353.908 \\
\end{array}$ & $\begin{array}{c}1,007 \\
-352.908 \\
\end{array}$ & $\begin{array}{c}1,391 \\
-411.258 \\
\end{array}$ & $\begin{array}{c}1,391 \\
-408.024 \\
\end{array}$ & $\begin{array}{c}1,391 \\
-396.497 \\
\end{array}$ & $\begin{array}{c}1,391 \\
-396.254 \\
\end{array}$ \\
\hline
\end{tabular}

